\title{
Detecção de mutações no gene KIT em leucemia mieloide aguda
}

\author{
The detection of KIT mutations in acute myeloid leukemia
}

Luis Eduardo Silva Machado ${ }^{1}$, João Renato Rebello Pinho ${ }^{1}$, Roberta Sitnik ${ }^{1}$, Nair Hideko Muto ${ }^{1}$,
Elvira Deolinda Rodrigues Pereira Velloso ${ }^{1}$, Roberta Cardoso Petroni ${ }^{1}$, Paulo Vidal Campregher ${ }^{1}$

\section{RESUMO}

Objetivo: Descrever a metodologia para detecção de mutações nos éxons 8 e 17 do gene KIT em pacientes portadores de leucemia mieloide aguda, para implementação desse teste no laboratório clínico do Hospital Israelita Albert Einstein. Métodos: Extração do DNA genômico de 54 amostras de sangue periférico ou medula óssea de pacientes com leucemia mieloide aguda para amplificação, por reação em cadeia da polimerase, sequenciamento e análise de fragmentos. Resultados: Dentre as amostras analisadas, quatro apresentaram mutação no éxon 8, duas no éxon 17 e uma amostra apresentou mutação nos dois éxons. Conclusão: A pesquisa de mutação nos éxons 8 e 17 do gene KIT foi padronizada com sucesso e o teste está em processo de inclusão no menu de exames do laboratório clínico do Hospital Israelita Albert Einstein.

Descritores: Leucemia mieloide aguda; Receptores proteína tirosina quinases; Fatores de ligação ao core; Expressão gênica

\begin{abstract}
Objective: This study describes a new method used in the clinical laboratory at Hospital Israelita Albert Einstein to detect mutations in exons 8 and 17 of the KIT gene in patients with acute myeloid leukemia. Methods: Genomic DNA extraction was performed on 54 samples of peripheral blood or bone marrow from patients with acute myeloid leukemia. The extracted DNA was amplified by polymerase chain reaction and sequenced, and the fragments were analyzed. Results: Within the analyzed samples, we detected four mutations in exon 8, two mutations in exon 17, and mutations or a double mutation in one sample. Conclusion: The tests detecting mutations in exon 8 and 17 on the KIT gene were successfully standardized. The test is now included among the routine diagnostics employed for patients at Hospital Israelita Albert Einstein clinical laboratory.
\end{abstract}

Keywords: Leukemia, myeloid, acute; Receptor protein-tyrosine kinase; Core binding factors; Gene expression

\section{INTRODUÇÃo}

A leucemia mieloide aguda (LMA) é uma neoplasia da medula óssea, caracterizada pela proliferação excessiva de células progenitoras mieloides (blastos), resultando em neutropenia, anemia e plaquetopenia ${ }^{(1)}$. Os principais determinantes prognósticos em LMA são o cariótipo e as alterações moleculares do blasto leucêmico, permitindo a classificação dos pacientes em grupos de risco de recidiva alto, intermediário e baixo. A classificação, segundo anormalidades citogenéticas e moleculares, pode ser vista na tabela 1 .

A definição terapêutica em LMA é, hoje, selecionada com base no risco de recidiva da doença, com pacientes de risco intermediário e alto sendo tratados com transplante de célula-tronco hematopoiética, e pacientes com risco baixo sendo tratados apenas com quimioterapia ${ }^{(2)}$.

As alterações cromossômicas t(8;21)(q22;q22) e $\operatorname{inv}(16)(\mathrm{p} 13 ; \mathrm{q} 22)$, que geram os rearranjos gênicos RUNX1-RUNX1T1 (AML1-ETO) e CBFB-MYH11, respectivamente, fazem parte do grupo citogenético de prognóstico favorável ${ }^{(3)}$.

Fisiopatologicamente, essas duas alterações são relacionadas, uma vez que alteram as subunidades alfa e beta, respectivamente, do complexo proteico chamado core binding factor (CBF), sendo, então, classificadas como leucemias CBF. Porém, cerca de $50 \%$ dos pacientes portadores de leucemia $\mathrm{CBF}$ apresentarão recaída da doença e altas taxas de mortalidade.

Dessa forma, a identificação de fatores de risco associados à recaída é fundamental para a correta estratificação prognóstica e tratamento adequado dos

\footnotetext{
Trabalho realizado no Serviço de Hematologia, Hospital Israelita Albert Einstein - HIAE, São Paulo (SP), Brasil.

Serviço de Hematologia, Hospital Israelita Albert Einstein - HIAE, São Paulo (SP), Brasil.

Autor correspondente: Paulo Vidal Campregher - Avenida Albert Einstein, 627/701 - Morumbi - CEP: 05651-901 - São Paulo (SP), Brasil - Tel.: (11) 2151-5555 - E-mail: paulo.campregher@einstein.br Data de submissão: 10/4/2012 - Data de aceite: 10/8/2012
}

Conflito de interesse: não há 
Tabela 1. Classificação prognóstica segundo anormalidades citogenéticas e moleculares

\begin{tabular}{|c|c|c|}
\hline Risco prognóstico & $\begin{array}{c}\text { Indicadores } \\
\text { citogenéticos }\end{array}$ & $\begin{array}{c}\text { Anormalidades } \\
\text { moleculares }\end{array}$ \\
\hline \multirow[t]{3}{*}{ Prognóstico favorável } & $\operatorname{inv}(16)$ ou t(16;16) & \multirow{3}{*}{$\begin{array}{l}\text { Citogenética normal: com } \\
\text { mutação NPM1 ou mutação } \\
\text { CEBPA isolada na ausência } \\
\text { de mutação FLT3-ITD }\end{array}$} \\
\hline & $\mathrm{t}(8 ; 21)$ & \\
\hline & $t(15 ; 17)$ & \\
\hline \multirow[t]{4}{*}{ Prognóstico Intermediário } & Citogenética normal & \multirow{4}{*}{$\begin{array}{l}\text { t(8;21), inv(16), t(16;16): } \\
\text { com mutação c-KIT }\end{array}$} \\
\hline & Trissomia do 8 & \\
\hline & $t(9 ; 11)$ & \\
\hline & Outros não definidos & \\
\hline \multirow[t]{6}{*}{ Prognóstico desfavorável } & $\begin{array}{l}\text { Cariótipo complexo } \\
\text { ( } \geq 3 \text { anormalidades } \\
\text { clonais cromossômicas) }\end{array}$ & \multirow[t]{6}{*}{$\begin{array}{l}\text { Citogenética normal: } \\
\text { com mutação FLT3-ITD }\end{array}$} \\
\hline & $-5,5 q-,-7,7 q-$ & \\
\hline & $11 q 23-\operatorname{sem} t(9 ; 11)$ & \\
\hline & $\operatorname{inv}(3), t(3 ; 3)$ & \\
\hline & $t(6 ; 9)$ & \\
\hline & $t(9 ; 22)$ & \\
\hline
\end{tabular}

Fonte: Extraída de http://www.nccn.org/professionals/physician__ls/pdf/aml.pdf.

pacientes portadores de leucemia CBF. Mutações no proto-oncogene KIT estão presentes em cerca de $25 \%$ dos pacientes portadores de $\operatorname{LMA~CBF}^{(4,5)}$.

Diversos estudos independentes demonstraram que a mutação em KIT está associada ao aumento do risco de recaída e à alta mortalidade em LMA CBF, mas os mecanismos ainda são desconhecidos ${ }^{(4-8)}$. Desse modo, a pesquisa de mutação no gene KIT é um teste essencial na avaliação prognóstica de pacientes portadores de LMA CBF.

\section{OBJETIVO}

Descrever o desenvolvimento de um novo teste in house, utilizando três metodologias complementares (sequenciamento de DNA, análise de fragmentos e conformationsensitive gel electrophoresis - CSGE), para pesquisa de mutação em KIT em pacientes com LMA e para posterior implantação do método no laboratório clínico do Hospital Israelita Albert Einstein (HIAE).

\section{MÉTODOS}

\section{Amostras}

Foram utilizadas amostras de medula óssea ou sangue total de pacientes portadores de LMA $(n=54)$, previamente analisadas no Laboratório Clínico do HIAE, para avaliação citogenética e molecular. Desses pacientes, 23 eram portadores de leucemia CBF.

\section{Extração de DNA genômico}

O DNA genômico foi extraído utilizando-se kits comerciais, segundo as instruções dos fabricantes: QIAamp DNA minikit (QIAGEN, Hilden, Alemanha), para amostras de sangue total, e Brazol (LGC Biotecnologia, São Paulo, Brasil), para amostras de medula óssea fixadas em solução metanol:ácido acético, com volume final de eluição de $50 \mu \mathrm{L}$. O DNA extraído foi quantificado utilizando espectrofotômetro NanoDrop 2000 (Thermo Scientific, USA) e diluído, resultando em concentrações finais entre 30 e $50 \mathrm{ng} / \mu \mathrm{L}$.

\section{Detecção de mutações dos éxons 8 e 17 do gene KIT} Como as mutações no gene KIT presentes em CBF LMA concentram-se nos éxons 8 e $17^{(5)}$, esses dois éxons foram escolhidos para o estudo. $\mathrm{O}$ padrão mutacional difere entre os dois éxons, caracterizando-se por mutações em ponto no éxon 17 e inserções e deleções no éxon 8. Dessa forma, optou-se pelo sequenciamento direto do produto da reação em cadeia da polimerase (PCR) para detecção das mutações no éxon 17 e PCR com primer marcado, seguida por eletroforese capilar e análise de fragmentos, para detecção das mutações no éxon 8. Foram selecionados pares de primers já descritos na literatura ${ }^{(5)}$ para o estudo desse gene, e a análise de especificidade destes foi feita com a ferramenta PCR in silico, [http://genome.ucsc.edu/cgi-bin/ hgPcr?command=start]. Posteriormente, um novo primer reverso foi desenhado para o éxon 17, permitindo uma melhor análise dessa região.

A validação inicial das reações de PCR incluiu variações nas concentrações de $\mathrm{MgCl} 2$ e primers, além de testes com gradiente de temperatura (anelamento entre 51 e 71,5ํㅡ) e adição de dimetilsulfóxido (DMSO) a 4\%. Após comparação dos resultados, foram selecionadas as condições ideais para as reações. A detecção de mutações no éxon 8 por eletroforese capilar foi inicialmente testada também por sequenciamento direto do produto de PCR e por CSGE. Os detalhes desses processos são os seguintes.

\section{Amplificação e detecção de mutações no éxon 17}

Para a amplificação dessa região, os primers utilizados inicialmente foram os descritos por Boissel et al. ${ }^{(5)}$, gerando um produto de 294pb: c-Kit éxon $17 \mathrm{FW}$ 5'-TGGTGTACTGAATACTTTAAAACAAAA-3'; c-Kit éxon 17 RV 5'-TGCAGGACTGTCAAGCAGAG-3'.

Posteriomente, oprimerreverse foi substituído, gerando um produto de $435 \mathrm{pb}$ : c-Kit éxon 17 reverse 2 - TAG TAATGTTCAGCATACCATGCAAATT. 
A reação de $\mathrm{PCR}$ foi realizada utilizando mix de $1 \mathrm{x}$ PCR buffer, $\mathrm{MgCl} 21 \mathrm{mM}$, dNTPs $0,2 \mathrm{mM}$, primers c-Kit $17 \mathrm{FW}$ e RV $0,16 \mu \mathrm{M} 1 \mathrm{U}$ de Taq polimerase, $2 \mu \mathrm{L}$ de DNA genômico (com concentração entre 30 e $50 \mathrm{ng} / \mu \mathrm{L}$ ) e água estéril qsp., totalizando um volume de reação de $25 \mathrm{uL}$. O programa da termociclagem consistiu de denaturação inicial a $94^{\circ} \mathrm{C}-5^{\prime}, 35$ ciclos de $94^{\circ} \mathrm{C}-45^{\prime \prime}$, $56^{\circ} \mathrm{C}-45^{\prime}, 72^{\circ} \mathrm{C}-45^{\prime \prime}$ e extensão final a $72^{\circ} \mathrm{C}$. Alíquotas do produto de PCR foram submetidas à eletroforese em gel de agarose a $2 \%$ para avaliação do sucesso da amplificação.

Os produtos de PCR foram purificados em coluna (Illustra GFX ${ }^{\mathrm{TM}}$ DNA and Gel Purification Kit, GE Healthcare, UK) e a reação de sequenciamento foi feita com o kit Bigdye ${ }^{\circledR}$ v3.1 (Applied Biosystems, USA) e com cada um dos primers de amplificação, em uma concentração de $1,6 \mu \mathrm{M}$, para que fosse obtida a leitura das duas fitas. O sequenciamento foi feito em um sequenciador automático ABI PRISM 3500xL (Applied Biosystems, USA) e as sequências obtidas foram analisadas no programa SeqScape ${ }^{\circledR}$ software v2.7 (Applied Biosystems, USA) pelo alinhamento com sequência referência.

\section{Amplificação e detecção de mutações no éxon 8}

Para a amplificação dessa região, os primers utilizados foram os descritos por Boissel et al. ${ }^{(5)}$, gerando um produto de 219pb: c-Kit éxon 8 FW 5'-GCTGAGGTT TTCCAGCACTC-3'; c-Kit éxon 8 RV 5'-AATTGCA GTCCTTCCCCTCT-3'.

A reação de PCR e as condições de termociclagem foram iguais aos do éxon 17. Para análise por eletroforese capilar, o primer forward foi marcado com FAM na extremidade 5'.

Inicialmente, os produtos de PCR foram sequenciados como descrito para o éxon 17 e, nos casos em que foram encontradas alterações sugestivas de mutações no éxon 8, esses produtos foram posteriormente analisados pela realização de CSGE. A reação CSGE consistiu na denaturação dos produtos de PCR por 5' a $98^{\circ} \mathrm{C}$, seguida por etapa de reanelamento por $30^{\prime}$ a $65^{\circ} \mathrm{C}$, para a formação de heterodúplex (anelamento de uma fita sem a mutação com uma fita mutada). O heterodúplex pode ser detectado por meio da diferença de migração em gel de agarose $4 \%$ corado com brometo de etídio. A segunda estratégia para a detecção dessas mutações foi a análise de fragmentos por eletroforese capilar, utilizando analisador genético automático ABI PRISM 3500xL (Applied Biosystems, USA).

A reação de PCR foi realizada nas mesmas condições descritas anteriormente. Produtos de PCR foram diluídos 30 vezes em água estéril e foi utilizado $1 \mu \mathrm{L}$ para a reação. Além disso, esses produtos foram adicionados a $8,7 \mu \mathrm{L}$ de formamida e $0,3 \mu \mathrm{L}$ de size standard (GeneScan $^{\mathrm{TM}} 500$ LIZ $^{\circledR}$, Applied Biosystems, UK). A mistura foi incubada por $3^{\prime}$ a $95^{\circ} \mathrm{C}$ e, em seguida, submetida a resfriamento em gelo por 2'. As amostras foram aplicadas no analisador genético e analisadas com GeneMapper software v4.1 (Applied Biosystems, USA) para verificação dos tamanhos dos fragmentos obtidos.

\section{Sensibilidade}

Após a padronização das reações, foi verificada também a sensibilidade da reação para pesquisa de mutação em cada éxon. Para isso, utilizaram-se produtos de PCR de uma amostra com aproximadamente 50\% das células mutadas diluída em uma amostra selvagem, em concentrações de DNA equivalentes. Posteriormente, foi realizada uma diluição seriada nas seguintes proporções: 1/1,1/2, 1/4 e 1/8, para detectar qual a porcentagem mínima de produto mutado seria detectável.

Este trabalho foi aprovado pelo comitê de ética e pesquisa do HIAE (processo 1.663/11).

\section{RESULTADOS}

\section{Detecção das mutações nos éxons 8 e 17}

Foram analisadas 54 amostras de pacientes portadores de LMA, sendo que, desse total, 31 amostras (LMA1) eram provenientes de pacientes sem as alterações características de LMA CBF e 23 apresentavam LMA CBF (LMA2) sendo 16 com t(8;21) e 7 com inv(16).

Nenhuma das amostras dos pacientes do grupo LMA1 apresentou mutações no gene KIT. As amostras desse grupo foram previamente estudadas para as mutações nos genes FLT3 e NPM1. Na análise inicial dos pacientes do grupo LMA2, feita apenas por sequenciamento dos produtos de PCR, observou-se que um paciente apresentava um padrão de sequência sugestivo de deleção e/ou inserção no éxon 8 (Figura 1).

Para confirmação da hipótese de deleção ou inserção, dois testes foram utilizados: CSGE e análise de fragmentos. Ambos confirmaram a presença de dois produtos, caracterizando deleção de quatro nucleotídeos (Figuras 2 e 3) no éxon 8 do gene KIT. A partir desse momento, passou-se a utilizar a análise de fragmentos como único teste para detecção de mutações no éxon 8. A reação de sequenciamento do éxon 17 com os primers descritos revelou sequências de baixa qualidade para análise de alguns códons importantes (códons 825, 826 e 828). Como solução para esse problema, desenhou-se um novo primer reverso, mais distal, de modo que 


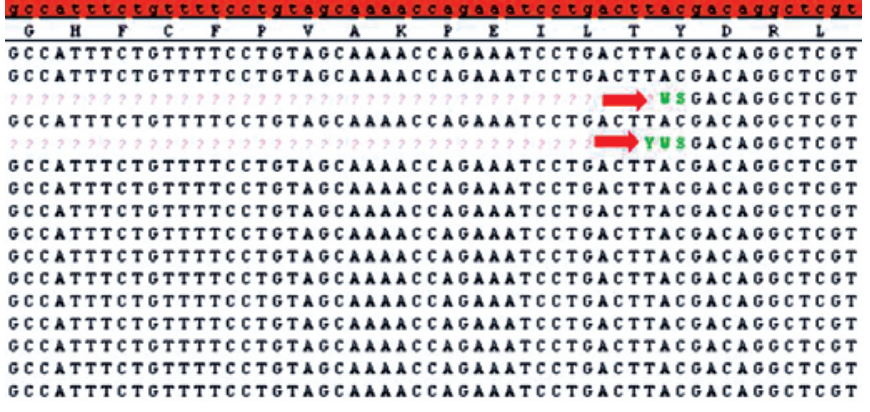

Figura 1. Sequenciamento automático de amostras do Grupo LMA2. Alterações na sequência genômica são evidenciadas por ambiguidade de nucleotídeos em uma única posição da região genômica do éxon 8 , indicada pelas letras $Y$, W, S (nomenclatura segundo IUPAC). As sequências com as setas vermelhas pertencem à mesma paciente, portadora de mutação no éxon 8 do gene KIT

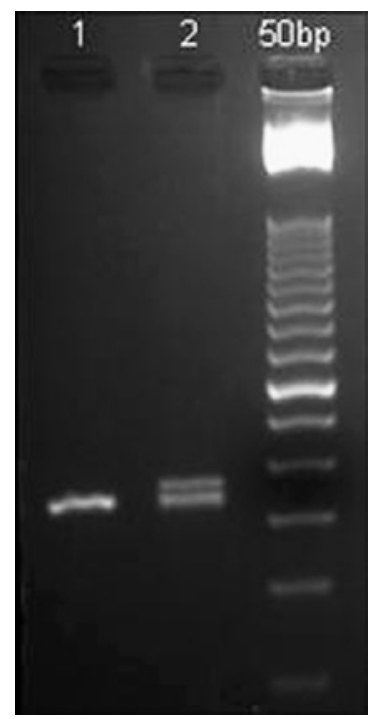

Figura 2. Eletroforese em gel de agarose dos produtos formados após a reação de CGSE (conformation-sensitive gel electrophoresis). Amostra 1: paciente sem alteração na sequência, sem a formação de heterodúplex. Amostra 2: paciente com alteração na sequência, com a formação de heterodúplex, evidenciando a presença da mutação no éxon 8
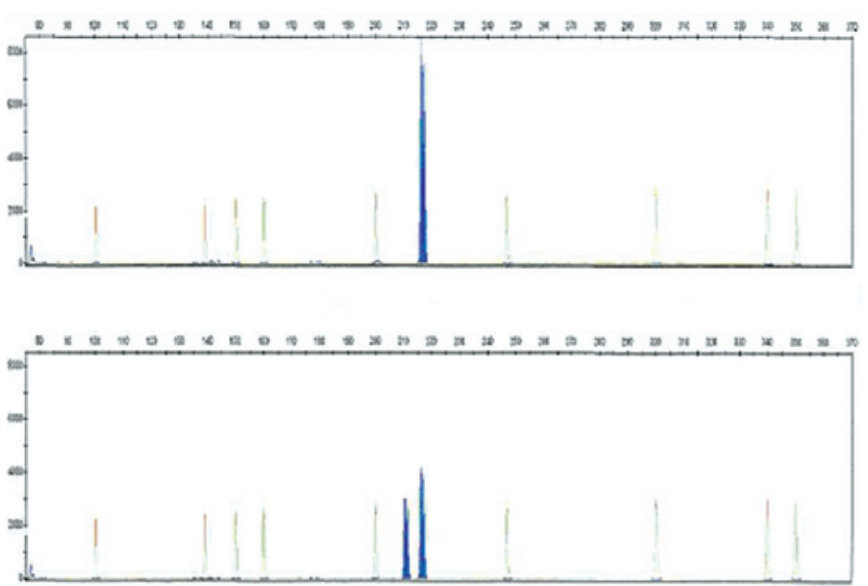

Figura 3. Análise de fragmento por eletroforese capilar. (A) Pico único $(218 \mathrm{pb})$ : amostra sem a mutação. (B) Pico duplo (215pb e 218pb): amostra com mutação, nesse caso, deleção de três nucleotídeos a região do gene acometida por mutações (códons 801 ao 828) ficasse distante dos primers de sequenciamento, melhorando, assim, a qualidade das sequências.

A análise completa das amostras do grupo LMA2 revelou a presença de mutação no gene KIT em sete casos. Destes, quatro pacientes apresentaram mutação no éxon 8, dois pacientes no éxon 17 (Figura 4) e um paciente apresentou mutação em ambos os éxons 8 e 17 (Tabela 2). Infelizmente, não há informações a respeito do seguimento clínico desses pacientes, uma vez que o trabalho foi realizado com amostras previamente armazenadas no laboratório e muitos dos pacientes não são acompanhados na instituição.
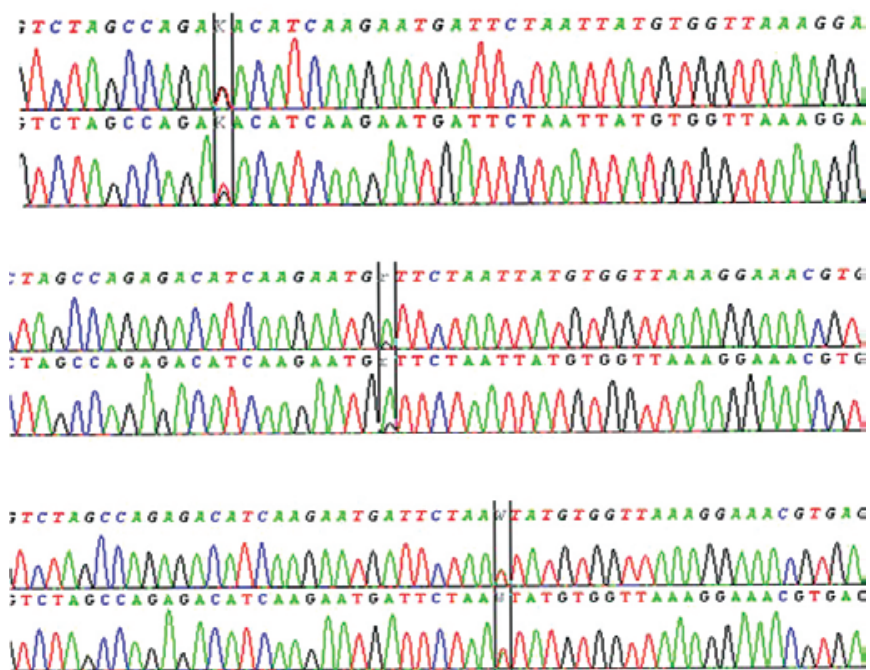

Figura 4. Eletroferogramas dos pacientes 1, 2 e 3 (vide tabela 2) demonstrando as mutações em heterozigose no éxon 17

Tabela 2. Mutações do gene KIT em pacientes com leucemia mieloide aguda segundo o éxon envolvido

\begin{tabular}{llll}
\hline Paciente & Cariótipo & \multicolumn{1}{c}{ Éxon 17 } & \multicolumn{1}{c}{ Éxon 8} \\
\hline 1 & $t(8 ; 21)$ & D816Y & Ausência de mutação \\
2 & $t(8 ; 21)$ & D820G & Deleção de 3 nucleotídeos \\
3 & $t(8 ; 21)$ & N822K & Ausência de mutação \\
4 & $t(8 ; 21)$ & Ausência de mutação & Deleção de 3 nucleotídeos \\
5 & $\operatorname{inv}(16)$ & Ausência de mutação & Inserção de 6 nucleotídeos \\
6 & $\operatorname{inv}(16)$ & Ausência de mutação & Deleção de 6 nucleotídeos \\
7 & $\operatorname{inv}(16)$ & Ausência de mutação & Deleção de 3 nucleotídeos \\
\hline
\end{tabular}

\section{Sensibilidade}

Os resultados dos testes de sensibilidade mostraram que a mutação no éxon 8 pode ser detectada até o mínimo de $5 \%$ de alelos mutados, por meio da técnica de eletroforese capilar. Para o éxon 17, a sensibilidade en- 
contrada foi de até $12,5 \%$ de alelos mutados na amostra por meio de sequenciamento Sanger.

\section{DISCUSSÃO}

A detecção de mutações no gene KIT tornou-se essencial na avaliação diagnóstica de pacientes portadores de LMA CBF. Estudos anteriores identificaram mutações nesse gene em cerca de $25 \%$ dos pacientes com LMA $\mathrm{CBF}^{(4,5)}$.

Enquanto pacientes portadores de LMA CBF e KIT selvagem apresentam um prognóstico favorável quando tratados apenas com quimioterapia ${ }^{(9,10)}$, a presença de mutação em KIT nesse grupo de pacientes se associa à diminuição na sobrevida livre de doença ${ }^{(11)} \mathrm{e}$ sobrevida global ${ }^{(7,8)}$. Esse fato levou à inclusão da pesquisa de mutação em KIT na classificação prognóstica do National Comprehensive Cancer Network (NCCN) e, atualmente, existe uma tendência a se indicar o transplante de célula-tronco hematopoiética, em primeira remissão completa, para pacientes portadores de LMA CBF e KIT mutado ${ }^{(12)}$.

No presente estudo, padronizou-se a pesquisa de mutação nos éxons 8 e 17 do gene KIT. Para isso, utilizaram-se primers descritos na literatura e desenharam-se novos primers, que permitiram melhor avaliação do produto do sequenciamento. Utilizaram-se três técnicas distintas para a detecção das mutações e padronizaram-se duas delas para uso na rotina do laboratório. Mutação no gene KIT foi detectada em 7 de 23 pacientes com LMA CBF, porém, estudos adicionais, em fase inicial no laboratório do HIAE, inclusive com um maior número de pacientes, são necessários para estimar a real frequência dessas mutações em nossa população. Em conformidade com a literatura, todas as mutações foram detectadas em pacientes do grupo LMA2, com CBF LMA ${ }^{(13)}$. Não foram encontradas mutações em KIT em outros tipos de LMA. As mutações foram detectadas no éxon 8 ou 17, e um paciente possuía os dois éxons mutados. Embora tenham sido utilizadas amostras arquivadas no laboratório do hospital, esse teste permitiria a reclassificação dos pacientes estudados de um grupo de baixo risco para um grupo de alto risco de recaída, melhorando, assim, a estratificação prognóstica deles.

Conforme aqui descrito ${ }^{(13)}$, as mutações no éxon 8 se caracterizaram por inserções e deleções, enquanto as do éxon 17 eram mutações em ponto, de modo que as primeiras são detectáveis por análise de fragmentos, enquanto as segundas devem ser detectadas por sequenciamento.
Finalmente, as quatro inserções ou deleções detectadas no éxon 8 foram todas múltiplas de três nucleotídeos, mantendo, assim, a matriz de leitura, de acordo com relatos prévios ${ }^{(14)}$. A sensibilidade dos testes (5\% para análise de fragmentos e $12,5 \%$ para sequenciamento) está de acordo com dados históricos e revela-se adequada para análise de amostras ao diagnóstico (sendo que estas, por definição, apresentam, no mínimo, $20 \%$ de células neoplásicas).

No entanto, se, no futuro, a pesquisa de mutação em KIT for utilizada para detecção de doença residual mínima, ensaios mais sensíveis, como PCR aleloespecífico, por exemplo, são necessários.

Parte dos pacientes analisados neste trabalho já havia sido avaliada em um estudo anterior, acerca da mutação nos genes FLT3 e NPM1 ${ }^{(15)}$. Nenhum dos pacientes com mutação nesses dois genes apresentou mutação concomitante em KIT. Como a pesquisa da mutação em KIT está incluída no algoritmo de diagnóstico e tratamento de NCCN, esse teste será incorporado ao laboratório clínico do HIAE. O presente estudo enfatiza, ainda, a necessidade de se incorporarem, à rotina diagnóstica, novos marcadores genéticos para a correta estratificação prognóstica e orientação terapêutica em leucemias agudas.

\section{CONCLUSÃO}

No presente trabalho, foi descrito o desenvolvimento in house e a padronização de um novo teste para a detecção de mutações no gene KIT. Mutações em KIT foram detectadas em sete pacientes portadores de LMA CBF. A disponibilização desse teste diagnóstico representará um avanço no tratamento de pacientes portadores de LMA CBF, possibilitando melhor estratificação prognóstica e definição adequada de conduta.

\section{REFERÊNCIAS}

1. Estey E, Döhner H. Acute myeloid leukaemia. Lancet. 2006;368(9550):1894-907.

2. Döhner H, Estey EH, Amadori S, Appelbaum FR, Büchner T, Burnett AK, Dombret H, Fenaux P, Grimwade D, Larson RA, Lo-Coco F, Naoe T, Niederwieser D, Ossenkoppele GJ, Sanz MA, Sierra J, Tallman MS, Löwenberg B, Bloomfield CD; European LeukemiaNet. Diagnosis and management of acute myeloid leukemia in adults: recommendations from an international expert panel, on behalf of the European LeukemiaNet. Blood. 2010;115(3):453-74.

3. Grimwade D, Walker H, Oliver F, Wheatley K, Harrison C, Harrison G, et al. The importance of diagnostic cytogenetics on outcome in AML: analysis of 1,612 patients entered into the MRC AML 10 trial. The Medical Research Council Adult and Childrens Leukaemia Working Parties. Blood. 1998;92(7):2322-33.

4. Care RS, Valk PJ, Goodeve AC, Abu-Duhier FM, Geertsma-Kleinekoort WM Wilson GA, et al. Incidence and prognosis of c-KIT and FLT3 mutations in core binding factor (CBF) acute myeloid leukaemias. Br J Haematol. 2003; 121(5):775-7.

5. Boissel N, Leroy H, Brethon B, Philippe N, de Botton S, Auvrignon A, Raffoux E, 
Leblanc T, Thomas X, Hermine 0, Quesnel B, Baruchel A, Leverger G, Dombret H, Preudhomme C; Acute Leukemia French Association (ALFA); Leucémies Aiguës Myéloblastiques de l'Enfant (LAME) Cooperative Groups. Incidence and prognostic impact of c-Kit, FLT3, and Ras gene mutations in core binding factor acute myeloid leukemia (CBF-AML). Leukemia. 2006;20(6):965-70.

6. Cairoli R, Beghini A, Grillo G, Nadali G, Elice F, Ripamonti CB, et al. Prognostic impact of c-KIT mutations in core binding factor leukemias: an Italian retrospective study. Blood. 2006;107(9):3463-8.

7. Schnittger S, Kohl TM, Haferlach T, Kern W, Hiddemann W, Spiekermann K, et al. KIT-D816 mutations in AML1-ETO-positive AML are associated with impaired event-free and overall survival. Blood. 2006;107(5):1791-9.

8. Paschka P, Marcucci G, Ruppert AS, Mrózek K, Chen H, Kittles RA, Vukosavljevic T, Perrotti D, Vardiman JW, Carroll AJ, Kolitz JE, Larson RA, Bloomfield CD; Cancer and Leukemia Group B. Adverse prognostic significance of KIT mutations in adult acute myeloid leukemia with inv(16) and t(8;21): a Cancer and Leukemia Group B Study. J Clin Oncol. 2006;24(24):3904-11.

9. Byrd JC, Ruppert AS, Mrózek K, Carroll AJ, Edwards CG, Arthur DC, et al. Repetitive cycles of high-dose cytarabine benefit patients with acute myeloid leukemia and inv(16)(p13q22) or $t(16 ; 16)(p 13 ; q 22)$ : results from CALGB 8461. J Clin Oncol. 2004;22(6):1087-94.
10. Byrd JC, Dodge RK, Carroll A, Baer MR, Edwards C, Stamberg J, et al. Patients with $t(8 ; 21)(q 22 ; q 22)$ and acute myeloid leukemia have superior failurefree and overall survival when repetitive cycles of high-dose cytarabine are administered. J Clin Oncol. 1999;17(12):3767-75.

11. Nanri T, Matsuno N, Kawakita T, Suzushima H, Kawano F, Mitsuya H, et al. Mutations in the receptor tyrosine kinase pathway are associated with clinical outcome in patients with acute myeloblastic leukemia harboring $\mathrm{t}(8 ; 21)(\mathrm{q} 22 ; \mathrm{q} 22)$. Leukemia. 2005;19(8):1361-6.

12. Gupta V, Tallman MS, Weisdorf DJ. Allogeneic hematopoietic cell transplantation for adults with acute myeloid leukemia: myths, controversies, and unknowns. Blood. 2011;117(8):2307-18.

13. Malaise M, Steinbach D, Corbacioglu S. Clinical implications of c-Kit mutations in acute myelogenous leukemia. Cur Hematol Malign Rep. 2009;4(2):77-82.

14. Gari M, Goodeve A, Wilson G, Winship P, Langabeer S, Linch D, et al. c-kit proto-oncogene exon 8 in-frame deletion plus insertion mutations in acute myeloid leukaemia. Br J Haematol. 1999;105(4):894-900.

15. Velloso ED, Motta CH, Furtado JB, Bacal NS, Silveira PA, Moyses CB, et al. Molecular and cytogenetic abnormalities in acute myeloid leukemia: review and case studies. Einstein. 2011;9(2 Pt1):184-9. 